\title{
THE ELECTROPHORETIC PATTERNS OF NORMAL PLASMA ${ }^{1}$
}

\author{
By VINCENT P. DOLE, 2 with THE TECHNICAL ASSISTANCE of ESTHER BRAUN \\ (From the U.S. Navy Research Unit at The Hospital of The Rockefeller Institute \\ for Medical Research, New York)
}

(Received for publication March 29, 1944)

Normal plasma values as reported in the literature (1 to 6 ) show a fair general agreement which suffices for the recognition of gross abnormalities. For clinical purposes, however, the electrophoretic method will find its full use only when purely technical uncertainties are reduced well below the level of clinical interpretation. This report will give the results obtained with normal subjects, using what appears to be the best present technic (7), and a discussion of various uncertainties encountered in analysis of the data.

\section{TECHNIC}

Blood for anaiyses was taken from healthy young male subjects in a post-absorptive state, except as specifically noted. When anticoagulant was required, potassium oxalate was used. After separation of serum or plasma, a sample was taken for micro Kjeldahl determination (8) of total protein and albumin:globulin ratio according to the Kingsley modification (9) of the Howe sodium sulfate fractionation.

Electrophoretic technic followed a method previously described (7); for detailed description, this paper should be consulted. The buffer system, $0.1 \mathrm{~N} \mathrm{NaV}-0.02 \mathrm{~N} \mathrm{H} \mathrm{V,}$ giving a $\mathrm{pH}$ of 8.6 at $25^{\circ} \mathrm{C}$., not only minimizes asymmetry between ascending and descending patterns but also allows the appearance of a previously hidden component, namely, $\alpha_{1}$ globulin which falls between albumin and $\alpha$ globulin of the older notation (in Longsworth's notation $\alpha_{2}$ globulin). Use of the title, globulin, for the $\alpha_{1}$ component is arbitrary and may require later revision when its properties have been thoroughly studied. In addition, a cell of double the usual length is used, thus improving resolution. Figure 1 shows a typical normal pattern.

Plasma or serum, after a preliminary dilution with buffer (1 volume plasma, 2 volumes buffer), was dialyzed against buffer in the cold for 2 or more days. The proteins were caused to migrate in electric fields, averaging about 6.5 volts per $\mathrm{cm}$. for 180 to 200 minutes; under these conditions albumin, the leading component, had shifted 40 to $50 \mathrm{~mm}$.

1 The Bureau of Medicine and Surgery does not necessarily undertake to endorse views or opinions which are expressed in this paper.

Lieutenant Commander, Medical Corps, United States Naval Reserve.

V $=$ diethylbarbiturate. from the original boundary. To allow calculation of mobilities, the current was frequently measured during each run; in addition, the $\mathrm{pH}$ and the conductivity of both the protein and buffer solutions were measured.

No general agreement exists as to the best procedure for analyzing the photographed patterns. Difficulty in deciding whether to use the ascending or descending pattern or both, for calculation of concentrations and mobilities of components, arises from the same cause that leads to asymmetry between the patterns, namely, the establishment of small buffer concentration gradients at the boundaries of the protein components. Since the basis for estimating concentrations is the change of refractive index at the boundaries and since a coincident buffer gradient in itself produces a change of refractive index, it may be easily seen that the protein concentration as estimated from the area under any peak in the pattern is indefinite by a small additive term. In the descending pattern, protein components have moved away from the initial boundary position, leaving there a gradient of buffer salt which causes the $\epsilon$ peak in this pattern. Migration of proteins proceeds through the initial boundary site in the ascending channel, however; here is developed a larger gradient, known as the $\delta$ peak, which includes gradients of proteins as well as of buffer salts. These buffer

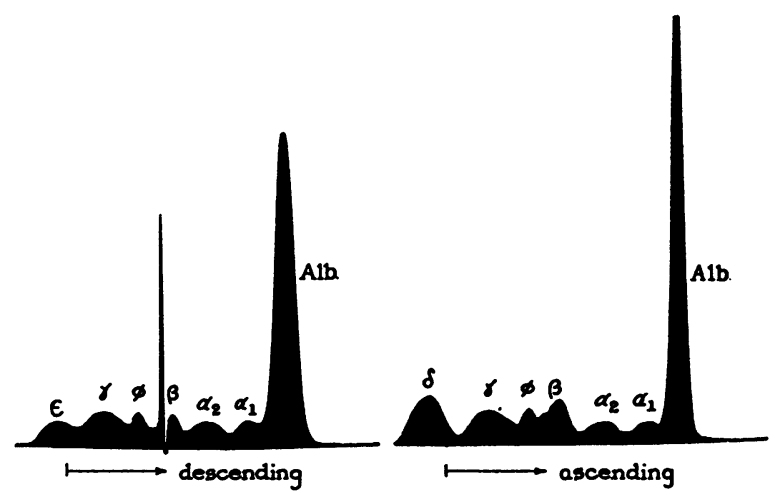

Fig. 1. Normal Plasma Pattern 
salt gradients, by causing local variations in $\mathrm{pH}$ and electric field, introduce uncertainties in the calculation of mobility.

There is as yet no adequate theory that would allow precise account for the effect of salt gradients. Lacking this, one must make various simplifying assumptions $(10,7)$. If it is assumed that, within the limits of necessary precision, the increments of refractive index due to salt gradients are proportional to the concentrations of proteins at the boundaries and by the same factor for each, these salt effects cancel out in the calculation of the relative proportions of the protein components which may then be determined as ratios of the corresponding areas. Use of the ascending pattern requires the additional assumption that in the $\delta$ boundary, the protein components maintain the same relative proportion as in the original specimens. It would perhaps be wiser to avoid the need of this additional assumption by restricting analysis to the descending pattern were it not that in this pattern, uncertainty arises from a disturbance in the region of the $\beta$ globulin component.

One test of the advisability of using both patterns to estimate proportions of proteins is found in comparison of values obtained from each
TABLE I

Comparison of the concentrations estimated for protein components in the ascending and descending patterns

As a preliminary calculation, the fractions of total protein area contributed by the protein components are measured in each pattern. This table shows for each component the ratio of the fraction estimated in the ascending pattern to the corresponding fraction estimated in the descending pattern. Values shown are the means and standard deviations of data calculated from 35 pairs of patterns.

$\alpha_{1}, \alpha_{2}, \beta, \phi, \gamma$ denote globulin components, where $\phi$ is fibrinogen.

\begin{tabular}{c|c|c|c|c|c|c}
\hline \hline Component & $\begin{array}{c}\text { Albu- } \\
\text { min }\end{array}$ & $\alpha$ & $\alpha$ & $\beta$ & $\phi$ & $\gamma$ \\
\hline Mean ratios $\frac{\text { ascending }}{\text { descending }}$ & 1.00 & 0.92 & 1.04 & 0.88 & 1.15 & 1.12 \\
\hline Standard deviation of ratios & \pm 0.050 & \pm 0.174 & \pm 0.187 & \pm 0.124 & \pm 0.177 & \pm 0.167 \\
\hline
\end{tabular}

pattern. Ratios, in each case, of the component area to the total area (exclusive of $\delta$ and $\epsilon$ boundaries) are calculated; under the above assumptions, they should measure the fraction of the total protein contributed by each component, hence they should be equal for corresponding components in both channels. Both normal and pathological subjects are included in this calculation as the issue is not of normality but of internal consistency in the method. As may be seen (Table I), the ratios of albumin fractions

TABLE II

\section{Multiple determinations on a single sample of blood}

Two migrations were done (serum and plasma) with 6 photographs in each at successive intervals. Time denotes minutes from start of migration. Spread shows displacement in mm: of ascending albumin peak from initial boundary. Components are designated as in Table I. The last 7 columns show ratios of area of component to total area of pattern (exclusive of $\delta$ and $\epsilon$ boundaries); values are averages of ascending and descending patterns.

\begin{tabular}{|c|c|c|c|c|c|c|c|c|c|}
\hline & Time & Spread & $\frac{\text { Alb. }+\alpha_{1}}{\text { Total }}$ & $\frac{\text { Alb. }}{\text { Total }}$ & $\frac{\alpha_{1}}{\text { Total }}$ & $\frac{\alpha z}{\text { Total }}$ & $\frac{\beta}{\text { Total }}$ & $\frac{\phi}{\text { Total }}$ & $\frac{\gamma}{\text { Total }}$ \\
\hline Serum & $\begin{array}{r}\min . \\
60 \\
90 \\
120 \\
150 \\
180 \\
210\end{array}$ & $\begin{array}{l}m m . \\
16.0 \\
23.0 \\
31.0 \\
38.5 \\
45.5 \\
49.5\end{array}$ & $\begin{array}{l}0.639 \\
0.659 \\
0.676 \\
0.677 \\
0.691 \\
0.664\end{array}$ & $\begin{array}{l}0.632 \\
0.634 \\
0.643 \\
0.618\end{array}$ & $\begin{array}{l}0.045 \\
0.043 \\
0.048 \\
0.047\end{array}$ & $\begin{array}{l}0.077 \\
0.078 \\
0.066 \\
0.070 \\
0.063 \\
0.070\end{array}$ & $\begin{array}{l}0.119 \\
0.111 \\
0.108 \\
0.112 \\
0.105 \\
0.110\end{array}$ & $\begin{array}{l}0 \\
0 \\
0 \\
0 \\
0 \\
0\end{array}$ & $\begin{array}{l}0.166 \\
0.154 \\
0.151 \\
0.143 \\
0.141 \\
0.156\end{array}$ \\
\hline \multicolumn{3}{|c|}{ Average } & 0.668 & 0.632 & 0.046 & 0.071 & 0.111 & 0 & 0.152 \\
\hline Plasma & $\begin{array}{r}60 \\
90 \\
120 \\
150 \\
180 \\
210\end{array}$ & $\begin{array}{l}16.0 \\
23.0 \\
31.0 \\
38.0 \\
44.5 \\
50.5\end{array}$ & $\begin{array}{l}0.648 \\
0.641 \\
0.646 \\
0.647 \\
0.651 \\
0.672\end{array}$ & $\begin{array}{l}0.602 \\
0.596 \\
0.601 \\
0.621\end{array}$ & $\begin{array}{l}0.044 \\
0.051 \\
0.050 \\
0.050\end{array}$ & $\begin{array}{l}0.073 \\
0.070 \\
0.056 \\
0.067 \\
0.063\end{array}$ & $\begin{array}{l}0.105 \\
0.102 \\
0.106 \\
0.096 \\
0.092\end{array}$ & $\begin{array}{l}0.051 \\
0.052 \\
0.057 \\
0.060 \\
0.052\end{array}$ & $\begin{array}{l}0.132 \\
0.132 \\
0.137 \\
0.128 \\
0.129\end{array}$ \\
\hline \multicolumn{3}{|c|}{ Average } & 0.651 & 0.605 & 0.049 & 0.066 & 0.100 & 0.054 & 0.132 \\
\hline \multicolumn{3}{|c|}{$\frac{\text { Average serum fraction }}{\text { Average plasma fraction }}$} & 1.03 & 1.04 & 0.94 & 1.08 & 1.11 & & 1.25 \\
\hline
\end{tabular}




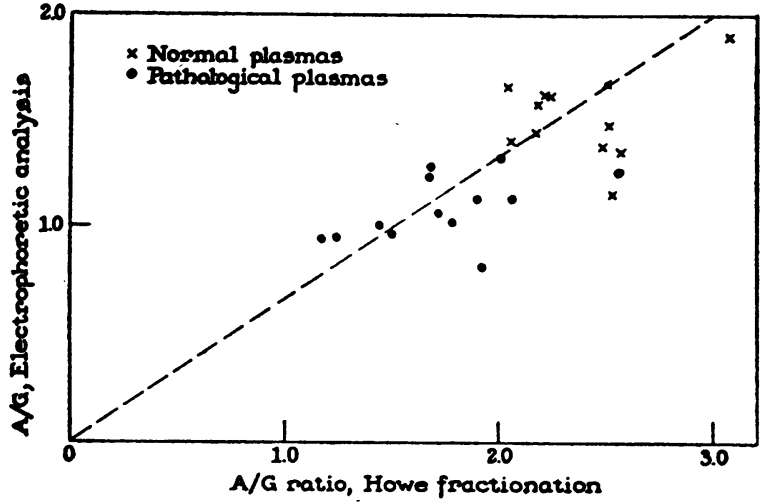

Fig. 2. Comparison of A/G Ratios Estimated from ElECTROPHORETIC ANALYSIS AND FROM NITROGEN Determination After Howe Fractionation

were found dispersed about a mean close to unity, indicating that no systematic influence affected this component. In the case of $\beta$ globulin, however, despite considerable variation it appears that a lower value is calculated from the ascending than the descending pattern; associated with this discrepancy, there must of course be complementary variations in the ratios of other globulin fractions since in both patterns, the sum of the fractions is unity. It thus is found that ratios of $\beta$ globulin + fibrinogen areas correspond closely, a fact that suggests that some of the difficulty might arise from uncertainty in allocating to each component its proper share of the total area in the graphical measurements. Accordingly, for the purpose of the present paper, the fractions of total protein assigned to components will be defined by the average of fractions calculated from the two patterns.

The problem of proper allocation of areas just encountered is one for which there is no satisfactory answer. It might appear that the ideal method is that of Pedersen (see Longsworth (7)) in which, starting from either end of a pattern, one reflects into the pattern a curve symmetrical about the axis of the peak, subtracts this curve from the ordinate of the pattern and proceeds to the next peak. However, the uncertainty that arises from the dubious assumption of complete symmetry of the peaks, inability to proceed through the $\beta$ globulin disturbance of the descending pattern, and cumulative graphical errors of the process leave no advantage to this method over the simpler procedure of Tiselius and Kabat (11). In this method, one drops a perpendicular to the base-line from the minima between peaks and assumes that the area for any component lost by overlap into adjacent areas is just offset by contribution of area by adjacent components. The approximation involved in this assumption may be expected to become progressively worse as peaks are crowded together to form a high curve with only shallow valleys separating the peaks.

As a test of the scatter to be expected from variable degrees of resolution, experiments were carried out in which photographs were taken at 30-minute intervals from 60 to 210 minutes after start of migration. For these 2 experiments, blood was taken from one individual, then divided between 2 tubes, one of which contained oxalate and the other no anticoagulant. Data obtained with the plasma and serum are shown in Table II. It is remarkable that even poorly resolved patterns give quite a good estimate of relative proportions.

This experiment also furnishes a test of the difference between serum and plasma since the material was obtained by division of a single sample. As a first approximation, the difference lies in disappearance of the fibrinogen component. If this were the only difference, one would expect that the fractions of total protein contributed by other components would be about 5 per cent greater in serum than in plasma owing to the fact that fibrinogen is present in the plasma in this amount. In the cases of $\beta$ and $\gamma$ globulin, the somewhat greater fractions found in the serum could be explained by the probable as-

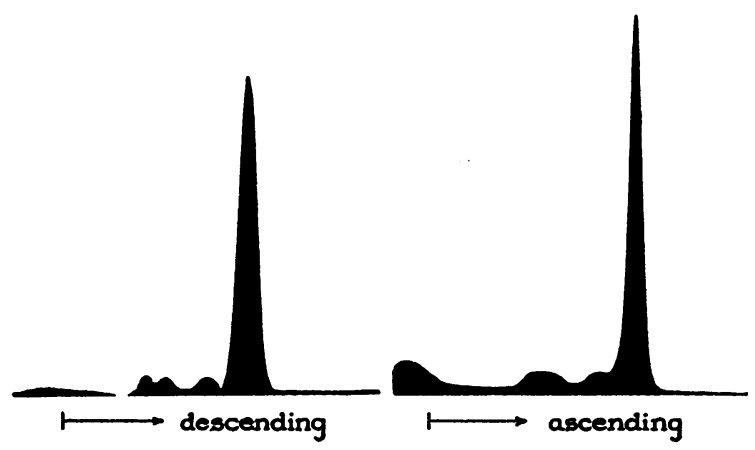

Fig. 3. Electrophoretic Pattern of Proteins in the "Albumin" Fraction After Sodium Sulfate Precipitation 
sumption that the narrow fibrinogen peak of the plasma pattern gains more area than it loses by overlap with these adjacent peaks. An actually lower value for the $\alpha_{1}$ fraction in serum than in plasma suggests the possibility that some of this component is removed when blood clots. More data are needed to establish the point.

\section{USE OF CHEMICAL DATA}

To the clinician, the usefulness of electrophoretic data might be enhanced by converting the ratios into absolute values since a ratio of two concentrations might be varied by change in value of either one or remain constant under proportional change of both. This conversion is accomplished by multiplication of the computed fraction of total protein contributed by various components into the chemically determined protein concentration, giving values for the components in grams per $100 \mathrm{cc}$. This is, of course, an arbitrary procedure since the various protein components doubtless vary in nitrogen content, but the uncertainties involved in this calculation probably are no greater than others inherent in the method. From data presented in this way, the original electrophoretic ratios are readily recalculated.

Chemical data also afford a comparison between albumin:globulin ratios measured chemically and electrophoretically. As shown in Figure 2, electrophoretic $A / G$ ratios tend to be systematically lower than the chemical values. A fraction measured as globulin by electrophoresis escapes precipitation by sodium sulfate, appears in the filtrate, and is measured as part of the "albumin" determined by Howe's method. This is shown in a pattern obtained with the "albumin" fraction (Figure 3) which remained in solution after the usual sodium sulfate fractionation. The supernatant solution was concen-

TABLE III

Comparison of distances migrated in the two channels (25 normal and pathological plasmas)

\begin{tabular}{c|c|c|c|c|c|c}
\hline \hline Component & $\begin{array}{c}\text { Albu- } \\
\text { min }\end{array}$ & $\alpha$ & $\alpha_{2}$ & $\beta$ & $\phi$ & $\gamma$ \\
\hline $\begin{array}{c}\text { Ratio of distances ascending } \\
\text { migrated }\end{array}$ & 1.06 & 1.10 & 1.13 & 1.12 & 1.16 & 1.13 \\
\hline \begin{tabular}{c} 
Standard deviation of ratio \\
\hline
\end{tabular} & \pm 0.011 & \pm 0.024 & \pm 0.033 & \pm 0.050 & \pm 0.044 & \pm 0.059 \\
\hline
\end{tabular}

Symbols as in Table I.

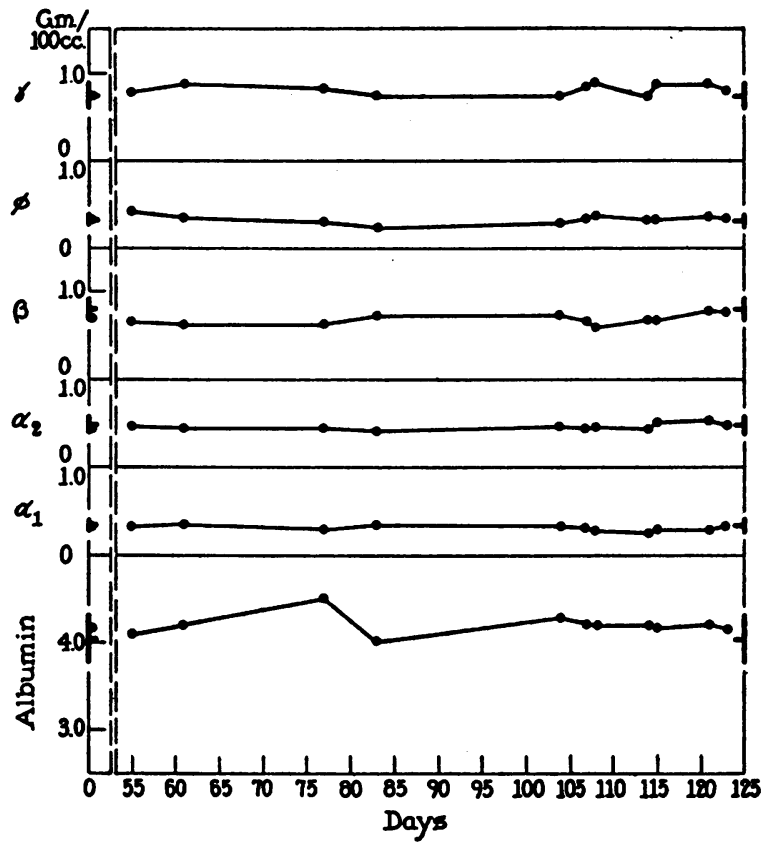

Fig. 4. Consecutive Observations of the Plasma OF ONE NORMAL INDIVIDUAL

On the ordinates are indicated the mean value and standard deviation for each component.

trated in a cellophane bag by alternate drying with an electric fan and dialysis against distilled water before final equilibration against buffer. It will be noted that an appreciable amount of globulin as defined from the electrophoretic patterns remains in solution. As measured, the electrophoretic $A / G$ ratio has a value of approximately $2 / 3$ of the chemical ratio determined on the same specimens of normal or pathological plasma; this is in fair accord with the relation which can be computed from data in the literature on normal and pathological plasmas. Although the scatter of this relation allows only rough calculation, it is possible to make some translation from the large body of data obtained by Howe's method to electrophoretic equivalents.

\section{Mobilities}

The apparent mobility of a component is affected by variation in protein concentration. Ideally, the data should be corrected to some standard state, such as infinite protein dilution in a given buffer, but the present knowledge of the salt and $\mathrm{pH}$ gradients throughout the cell is 
TABLE IV

Normal values (15 normal plasmas)

Components indicated are albumin, $\alpha_{1}, \alpha_{2}, \beta$ globulins, respectively, fibrinogen and $\gamma$ globulin. A/G denotes albumin globulin ratio. Concentrations are given as $r$ (ratio of component area to total area exclusive of $\delta$ and $\epsilon$ peaks) and as grams per $100 \mathrm{cc}$.

\begin{tabular}{|c|c|c|c|c|c|c|c|c|c|c|c|c|c|c|}
\hline \multirow{3}{*}{$\begin{array}{l}\text { Concentra- } \\
\text { tions }\end{array}$} & & \multicolumn{2}{|c|}{ Albumin } & \multicolumn{2}{|c|}{$\alpha_{1}$} & \multicolumn{2}{|c|}{$\alpha 2$} & \multicolumn{2}{|c|}{$\boldsymbol{\beta}$} & \multicolumn{2}{|c|}{$\phi$} & \multicolumn{2}{|c|}{$\gamma$} & \multirow{2}{*}{$\begin{array}{l}\mathrm{A} / \mathrm{G} \\
1.53\end{array}$} \\
\hline & Mean & $\begin{array}{c}r \\
0.603\end{array}$ & $\begin{array}{c}\text { grams } \\
\text { per } \\
100 \text { cc. } \\
4.04\end{array}$ & $\begin{array}{c}r \\
0.046\end{array}$ & $\begin{array}{l}\text { grams } \\
\text { per } \\
100 \text { cc. } \\
0.31\end{array}$ & $\begin{array}{c}r \\
0.072\end{array}$ & $\begin{array}{l}\text { grams } \\
\text { per } \\
100 \mathrm{cc} . \\
0.48\end{array}$ & $\begin{array}{c}r \\
0.121\end{array}$ & $\begin{array}{l}\text { grams } \\
\text { per } \\
100 \text { cc. } \\
0.81\end{array}$ & $\begin{array}{c}r \\
0.051\end{array}$ & $\begin{array}{l}\text { grams } \\
\text { per } \\
100 \text { cc. } \\
0.34\end{array}$ & $\begin{array}{c}r \\
0.110\end{array}$ & $\begin{array}{l}\text { grams } \\
\text { per } \\
100 \mathrm{cc} . \\
0.74\end{array}$ & \\
\hline & $\begin{array}{c}\text { Standard } \\
\text { deviation }\end{array}$ & 0.028 & 0.27 & 0.007 & 0.051 & 0.013 & 0.083 & 0.019 & 0.126 & 0.006 & 0.059 & 0.025 & 0.151 & \multirow[t]{3}{*}{0.181} \\
\hline \multirow{2}{*}{$\begin{array}{l}\text { Mobilities } \\
\left(\mathrm{cm}^{2} / \text { volt }\right. \\
\left.\text { sec. } \times 10^{5}\right)\end{array}$} & Mean & \multicolumn{2}{|c|}{5.94} & \multicolumn{2}{|c|}{5.07} & \multicolumn{2}{|c|}{4.08} & \multicolumn{2}{|c|}{2.83} & \multicolumn{2}{|c|}{2.14} & \multicolumn{2}{|c|}{1.02} & \\
\hline & $\begin{array}{c}\text { Standard } \\
\text { deviation }\end{array}$ & \multicolumn{2}{|c|}{0.267} & \multicolumn{2}{|c|}{0.236} & \multicolumn{2}{|c|}{0.256} & \multicolumn{2}{|c|}{0.241} & \multicolumn{2}{|c|}{0.252} & \multicolumn{2}{|c|}{0.282} & \\
\hline
\end{tabular}

too limited to allow this to be done without ambiguity. An alternative procedure described below appears to be a compromise adequate for the present purposes.

One protein component migrates in the original protein mixture, namely, albumin in the descending channel. Others, however, migrate in regions from which various components are missing since, in either channel, a protein component is present only below its boundaries. Thus, when a mixture is partially separated by electrophoresis, one would find in proceeding from pure buffer in one channel to pure buffer in the other, a stepwise increase of total protein concentration to a maximum of complete mixture at the center, then a complementary stepwise decrease on the other side. In the central region where all components are present, there is a region of protein and buffer gradients, the $\delta$ boundary, near the initial boundary position of the ascending channel. At all these steps the associated buffer gradients are of unknown magnitude but it would appear reasonable to assume that in the two channels, the globulin components are affected by oppositely directed influences. While albumin mobility was calculated from the velocity of the descending peak, therefore, globulin mobilities were based on average velocities in the two channels with $\mathrm{pH}$ and conductivity data of the original protein mixture.

An estimate of the discrepancies in the data from the two channels may be made from the data in Table III in which are given the ratios of migration distance for each component in ascending and descending patterns. Presumably the buffer gradients at the boundaries of globulin components are small; if this be assumed, it follows that the 6 per cent increment found for albumin is due to the $\delta$ boundary gradient. Increments for the globulins are larger, however. From this fact it is seen that the lengths of columns of globulins from their descending to their ascending boundaries are greater than the length of the albumin column. They must, therefore, either experience a greater relative concentration change than albumin through the $\delta$ boundary or there must be appreciable changes in globulin concentrations at the descending boundary of the albumin component. Either of these possibilities unsettles the calculation of protein concentrations, so that with this, as with mobility, the value of the data is comparative.

Purely graphical errors arise from the fact that the distance of migration should be measured from the initial boundary to the centroidal ordinate of a peak as it would appear in the absence of overlapping peaks. Because of the overlap of peaks, however, their true contours are unknown; distances were therefore determined using the maxima of the peaks. The systematic errors from this cause appear to be quite constant.

\section{Observations on the plasma of a single individual over a period of time}

For some purposes, more interest will attach to the changes in successive electrophoretic analyses using individual patients than to group 
averages of patients of a given disease type. Only one normal individual has been thus followed in consecutive observations (Figure 4). While this single series is not adequate to define the extent of normal fluctuation with time, it indicates a reasonable stability of the protein pattern. The causes of the small physiological variations found are at present not known. More variation is present than would be expected from technical errors in analysis.

\section{Normal standards}

In Table IV are given the values derived from the analysis of 15 plasmas, taken from normal young male adults, 4 or more hours after meals.

\section{SUMMARY}

Normal values for the concentrations and mobilities of protein components in human plasma have been determined by electrophoresis at $\mathrm{pH} 8.6$ in sodium veronal buffer. Albumin: globulin ratios, measured electrophoretically, were found to be roughly two thirds the ratio found by chemical fractionation of the same sample.

Various sources of technical uncertainty are discussed.

It is a pleasure to acknowledge the guidance of Drs. T. Shedlovsky, L. G. Longsworth, and D. A. MacInnes.

\section{BIBLIOGRAPHY}

1. Longsworth, L. G., Shedlovsky, T., and MacInnes, D. A., Electrophoretic patterns of normal and pathological human blood serum and plasma. J. Exper. Med., 1939, 70, 399.

Longsworth, L. G., and MacInnes, D. A., Electrophoretic study of nephrotic sera and urine. J. Exper. Med., 1940, 71, 77.

2. Kekwick, R. A., Electrophoretic analysis of normal human serum. Biochem. J., 1939, 33, 1122. Serum proteins in multiple myelomatosis. Biochem. J., 1940, 34, 1248.

3. Luetscher, J. A., Jr., Electrophoretic analysis of plasma and urinary proteins. J. Clin. Invest., 1940, 19, 313.

4. Moore, D. H., and Lynn, J., Electrophoretic measurements on normal human plasma. J. Biol. Chem., 1941, 141, 819.

5. Gutman, A. B., Moore, D. H., Gutman, E. B., McClellan, V., and Kabat, E. A., Fractionation of serum proteins in hyperproteinemia with special reference to multiple myeloma. J. Clin. Invest., 1941, 20, 765.

6. Taylor, H. L., and Keys, A., Fractionation of normal serum proteins by the electrophoretic and sodium sulfate methods. J. Biol. Chem., 1943, 148, 379.

7. Longsworth, L. G., Recent advances in the study of proteins by electrophoresis. Chem. Rev., 1942, 30, 323.

8. Van Slyke, D. D., Gasometric micro-Kjeldahl determination of nitrogen. J. Biol. Chem., 1927, 71, 235.

9. Kingsley, G. R., A rapid method for the separation of serum albumin and globulin. J. Biol. Chem., 1940, $133,731$.

10. Svensson, H., Fractionation of serum with ammonium sulfate and water dialysis, studied by electrophoresis. J. Biol. Chem., 1941, 139, 805.

11. Tiselius, A., and Kabat, E. A., Electrophoretic study of immune sera and purified antibody preparations. J. Exper. Med., 1939, 69, 119. 